\title{
INTERTEXTUAL RELATION FOR THE CREATION OF FASHION CONTENTS
}

\author{
Roberta Cesarino IAHN, \\ Faculdade Cásper Líbero - Faculty of Communication, São Paulo, Brazil. \\ robertaiahn@terra.com.br \\ Rodney NASCIMENTO \\ Faculdade Cásper Líbero - Faculty of Communication, São Paulo, Brazil. \\ rody70@,terra.com.br
}

\begin{abstract}
The objective of this study is to highlight the interference of information technology for the fashion creation. Fashion is no longer a content specific of designers or expert journalists, being resistant to the language reduction system (Barthes, 2005). The technological interference in the image of fashion allowed a broad interchange of signs orchestrated by different people and backgrounds. Digital photography and blogs expanded relations between fashion (creation and content) and street trends (authorial consumption) where idea and experience assume a creative value of market (Future Concept Lab). This intertextual relation between fashion creation and information of its contents has established a network of associations from which it feeds an aesthetic system that changes the issue of authorship (creation) and property (information). Fashion creation and production are in web pages in order to allow a creative movement out of ateliers and fashion publishing to democratize the structure of a very elitist market until then. The fashion world designed by good designers and described by powerful editors (Matharu, 2011) has received new participants that have brought different perceptions on culture, aesthetics, and identity. Major corporate brands need to interact with an opinion production and content that are out of the industrial axis and market - at the same time independent and free to provide feedback and set new standards of value. Thus, we understand that the conflict is set between the new content production model related to the old-fashioned system of fashion production. We will try to clarify this issue from this paper.
\end{abstract}

Keywords: Fashion, Blogs, Digital photography, Creation

\section{INTRODUCTION}

Studies aimed at the fashion image often do not receive adequate attention from academic research. The reason is the association of fashion to the study of appearances reducing its object of analysis to a capacity of social and economic differentiation in a location or time. Fashion, however, allows a critical reflection of society because, through its visual culture, it can establish connections between popular and erudite, creation and communication. Fashion is an object with a clear aesthetic function related to the meaning of everyday life, away from the stereotyped patterns of Vogue Magazine photo shoots, whatever it may be an icon of its representation as an industry and information. In studies of Mesquita and Preciosa (2011) fashion is seen through a web of signs where different territories of knowledge and creation are part of its construction by means of voices that find each other strange, also intertwining and complementing themselves. The technological culture of evidence is another important event that brought to the fashion environment a further possible interpretation of the trends and the way to develop and distribute its content. 
The relations created between fashion images and their connections with communication and technology allow us to reflect in this paper on the pulsating construction of interfaces which is not reduced to the appearance or distinction by clothing, but formalized in a creative movement out of workshops and fashion sections of specialized magazines, thus democratizing information, as well as the creation and opinion on the contemporary production of one of the most significant creative representations of a consuming society - fashion.

Fashion is no longer a unique content for designers or journalists once it allows the construction of a creative net that interacts with who can re-signify its language and aesthetics. This means that fashion can be written, discussed, or even elaborated by new channels and people, taking technology as a potentiator of sociability between individuals and their ideas.

So, nowadays the interference of technology in the content and communication in fashion is far beyond digital photography. Its participation is significant, but not exclusive. It was transformative, but not definitive. The Internet and the ability to disseminate information have been responsible for the expansion of social relationships, building new connections and languages between an aesthetic system once restricted to an territorial and marketing elite, currently owned by an extensive network of bloggers from the most diverse backgrounds and locations.

Thus, fashion as authorial consumption - customized, private and available on the world wide web (Internet) - presents a new creative and informative phase outside the traditional channels of this industry. In turn, this same industry started to need more and more a marginal creative construction as a method of hunting trends (coolhunters) to be renewed and refreshed. This article intends to discuss how technology intervened and modified intertextual relations in the creation of fashion content highlighting the modification of authorship issues and information ownership.

\section{DIGITAL LANGUAGE RE-SIGNIFIES THE CURRENT FASHION SCENERY}

The development of aesthetic perception is in the contemplation and understanding of multiple languages. When studying or just admiring literary, cinematographic or artistic works, the possibility of integrating a new creative universe is real. Different discourses and methods lead us to the act of creating. Fashion interacts with all art and media formats and perceived in the technology a chance to multiply its references.

We noted digital images interacting in all the places of the environments where we visited. From shop windows to websites, the image of fashion has been multiplied. Thus, it has also expanded its public - not more a passive and consumerist -, but a participatory and multiplier one. With the advent of Ipads, we no longer know what is communication without the convergence of so many integrated possibilities: text, photo, video, audio, animation, and especially the public participation in content collaboration. Fashion and advertising are at the forefront of creating new content and formats of digital interaction. In his writings on image and fashion, Roland Barthes reported to be rare to get "depth" in a content related to the consuming industry such as fashion and advertising, for "there is in the imagination of these practices the reign of a conformism totally submissive to models originated from a kind of vulgate of culture." (Barthes, 2005:120)

However, it was from the creation of content on digital platforms for fashion and advertising that a new cultural and artistic process with significant production confronted this view of Barthes. Even with restrictions and extreme attachment to the technique, ie, the platform for its development, language and digital image feed a wide network of associations. This network is superfluid, regardless of the marketing purpose of the content produced. It is a web that produces 
content and favors new experiences, especially enlarging the fabric of signs orchestrated by different people, cultures, and backgrounds. We can not affirm that this intertextual relation between creation, production, and information is not deep and qualitative, even if it is a relation linked to the aesthetic of consumption.

The digital creation is produced with explicit criteria. It also allows the study of its layers and shows the amplitude of the act of producing its final object. But there is still some resistance to the new technological culture of fashion today. It has appeared as a result of internet development and soon found itself disqualified to offer to everyone a possibility of choice and opinion. Vilém Flusser's philosophy about the encoded world presented a logic more relevant to the effects of technology and virtuality in aesthetic manifestations such as design, advertising, and fashion:

Mankind tries to overcome its physical limitations through technology. However, from now on, the experience of the world is to be governed by other codes and conventions, languages and projects that can reshape perceptions, much more than the landscape. (Flusser 2007: 47)

It is the appropriation of the things of the world as a creative reference and the creation of multipossibilities that force the interaction and choice, changing paths to criteria: when repeated they can become a trend and re-signify what existed before.

It is in a position of open dialogue (presenting "hot" interchanges in the trade of ideas and knowledge) that deflections can "take root" and then turn into trends. As we have seen countless times, the innovative (creative) evolution is always consumed by the transformation of deflections in trends. It is necessary that a new idea benefit the beginning of a cultural microeffervescence, "a splinter group in love" (Gaudin) from five to 15 people. So the fervent ones multiply the yeasts, which multiply the fervent ones, until the deflection becomes a trend. If it is considered victorious, it can become an orthodoxy and then impose a new standardization and a new imprinting in its sphere of domination.

(Morin, 2005: 38)

Thus, in this interaction appears the other with the external glance ready to exert his/ her influence or simply accept or not the object of that interaction. Citing Borges: "you the reader propose the meaning," so, an external glance has an incredible strength to the stimuli of creation and production. As much as our cultural relations condition us to break determinisms, the originality of an idea or a work is grounded in cultural pluralism. Morin mentions the cultural explosion of the Renaissance as an example of the formalization of the creation idea protected by a "statute of artists, writers, and thinkers" who were "recognized, protected, and admired." Then, it has been created a standard for the new.

Karin Rashid, a renowned Egyptian designer based in New York perceives the appeal of the digital world as a way to avoid damaging what has been done, since the public is better prepared for changes than companies. In the fashion scenery the resistance to open new ideas and productions to new formats is evident in the major brands in the industry. However, this new immaterial world created by the Internet favors big innovations coming out of unconventional places like suburban garages or teenager bedrooms. We need more and more design and technology to differentiate ourselves. Fashion blogs have become a provocative instrument in the market, then showing signs of fashion changed from the decline of the haute-couture and the invasion of fast-fashion. The globalized business environment has put the white T-shirt as the 
basic icon in fashion. It was also through it that the cotton planted in Bangladesh has become universally known. However, now, with the technological culture, Indian designers and those from other countries also have an opportunity to show their ideas out of the complex global supply chain and the official fashion weeks. They can use blogs, collective purchase websites, and mainly social networks.

\section{THE NEW MEMBERS OF THE CONTENT OF FASHION}

The researchers of trends observe the behavior of people and especially the correlation that these behaviors cause, ie, they seek to follow how someone can interfere in the choice of another person. So young people are multipliers of perceptions and behaviors that will be accepted, processed, and multiplied by so many others. Thus, when they create or produce information through the Internet, they present an immense capacity to rally followers.

These researchers are observatories that help us to interpret some behavioral movements that are actually comprehensive cultural movements that spread to all continents. Journalist and president of Future Concept Lab in Milan Francesco Morace, in his latest research of trends, included a team of fifty correspondents in some 40 countries, including Brazil, to observe and record the daily cultural and behavioral phenomena among young people all over the world that could also present global trends in their manifestations. The sociological analysis of this research has demonstrated that instability is the rule of the contemporary game. And moments of crisis reveal a pure material of anxieties and doubts that will allow us to read and interpret the mind of this generation, which is connected in networks, exchanges information, and creates a new way of seeing the world: "the engine that drives the contemporary individual does not stop. Our homo sapiens still evolves wishing, inciting, accepting, imposing... " (Morace, 2009:7)

A change in behavior between generations is nothing new. But, our myopia can deceive us just because we believe that these movements are cyclical and similar. By accepting this, we forget the accumulation of changes in the last century which never happened at any other time in history. Information, communication, technology, and interactivity unprecedentedly changed our perception of time. The speed of these changes were not gradual. They changed the way we think and experience the experiences of the world. They are less elitist and penetrated in several types of human groups. According to an introduction of Castells (1999): "our world and lives have been shaped by the conflicting trends of globalization and identity." For him, the revolution in information technology has introduced a new model - the net society, which has as main characteristic the globalization of economic activities, flexibility, job insecurity, and the individualisation of manpower.

The virtual world starts to get a real appearance through the "ubiquitous, interconnected, and highly diversified" media stimulus. Thus, the knowledge makes everything simpler, just leaving the problem to a formal industry that does not understand this way of building relations. When it refuses to be part of this network, it disrupts the dialogue and any possibility of interaction.

\section{CONCLUSIONS}

The Internet is an important communication tool for the dissemination of ideas and products globally. From super brands to the unknown or beginning brands, all of them strive to create websites, blogs, and profiles on major social networks as a way to integrate this new concept of virtual communication. But this is not enough. The concepts of communication of a brand are still created in conjunction with designers from fashion brands to communicate an identity, which has the function to influence specific publics, change attitudes, and create iconic moments that can be identified with a brand. 
The movement created by the technological culture of fashion came up with the blogs elaborated mostly by young women who love fashion, opine, and have a sizeable group of followers. These are bloggers who are becoming responsible for the spread of brand identities. Thus, the traditional form of disclosure of fashion has been changed dramatically. Who indicates which is the ideal brand is the same person that writes about it and translates its actions for behaviors similar to the identity the style of that brand wants to reveal, but far from conventional advertising and engaging with the experience of the brand and its products.

The communication of fashion was based on the following principles: ideal, aesthetics, style, and attitude. The fashion came from the runway, went to museums but is now struggling to interact with the public that increasingly assigns relevance to it: this public portrays fashion in the purest form it may have by opining freely and setting new standards of values.

Some blogs like http://www.stylescrapbook.com/ and http://carolinesmode.com contribute to resignify the aesthetic system of fashion with new participants that are not originated from the conventional structure. In his book Blog, Hugh Hewitt understands the revolution and compares the importance of the proliferation of blogs and their influence in communications to the invention of printing credited to Johannes Gutenberg, who created a new mechanical press. (Averbach, 2007:44)

A remarkable fact is that today there is a greater number of blogs and female bloggers registered for the coverage of fashion weeks than magazines or broadcast channels. Small or large brands are beginning to perceive blogs as a more targeted communication and relation way. However, fashion consultants reknown in the Brazilian market such as Gloria Kalil still consider that the public has no ability to decode the fashion information disclosed by so many fashion blogs. Could it be that the content produced by fashion blogs does not help in creating a multi-repertoire so easily personified, and so a mediator of new meanings?

\section{REFERENCES}

[1] Barthes, R. (2005). Inéditos: moda e imagem, São Paulo: Martins Fontes.

[2] Castells, M. (1999). O poder da identidade. São Paulo: Paz e Terra.

[3] Flusser, V. (2007). O mundo codificado. São Paulo: Cosac Naify.

[4] Garcia, C. \& Miranda, A.P.(2010). Moda é comunicação, São Paulo: Anhembi Morumbi.

[5] Morace, F.(2009). Consumo autoral, São Paulo: Estação das Letras e Cores.

[6] Morin, E.(2005). O método 4: as ideias - habitat, vida, costumes, organização. Porto Alegre: Sulina.

[7] Mesquita, C. \& Preciosa, R.(2011). Moda em Ziguezague, São Paulo: Estação das Letras e Cores.

[8] Averbach, B.(2007). A moda dos blogs e os blogs de moda in: Dobras. São Paulo, volume 1, número 1, Estação das Letras e Cores. 